\title{
The Effect of Synectic Learning Models in Developing Student Creativity
}

\section{Pengaruh Model Pembelajaran Sinektik Dalam Mengembangkan Kreativitas Peserta Didik}

OPEN ACCESS ISSN 2579-5813 (online)

Edited by: Nurdyansyah Nurdyansyah

Reviewed by: Hartono Hartono,

Nuril Nuzulia

*Correspondence: Yulia Pramusinta

yulia1@gmail.com

Received: 21 September 2020 Accepted: 25 September 2020 Published: 30 September 2020

Citation:

Pramusinta Y and Rifanah FD (2020)

The Effect of Synectic Learning Models in Developing Student

Creativity.

Madrosatuna: Journal of Islamic

Elementary School. 4:2.

doi: 10.21070/madrosatuna.v4i2.10

\author{
Yulia Pramusinta*, Farah Destria Rifanah \\ Program Studi Pendidikan Guru Madarasah Ibtidaiyah, Fakultas Agama Islam, Universitas Islam Lamongan, Indonesia
}

In the 21st century, one of the learning outcomes that students must have is creativity. Creating creative human resources can be through education or learning, one of which is by using a synectic learning model. The synectic learning model has a syntax that can foster student creativity. This study aimed to examine differences in the creative learning outcomes of students who are taught with the synectic model and students who learn using conventional learning models. The research method used is quasi-experimental. This research was conducted in January-February 2020. The population of this study was students in grade 3 at MI Bahrul Ulum Blawi with Indonesian subjects. The sampling method used was cluster random sampling. In this study, the sample was 2 classes using random sample sampling, one class as a control class taught using conventional methods, and one class as an experimental class taught using the synectic learning model. The number of research subjects in the experimental class was 22 students, and the control class consisted of 20 students. The research analysis used an independent sample t-test. The study results concluded that there was an influence between the synectic learning model on students' creativity in Indonesian lessons.

Keywords: Effectiveness, Synectic Learning, Creativity

Pada era abad 21 salah satu hasil belajar yang harus dimiliki oleh siswa adalah kreatifitas. Menciptakan sumberdaya manusia yang kreatif dapat melalui pendidikan atau pembelajaran salah satunya dengan menggunakan model pembelajaran sinektik. Model pembelajaran sinektik mempunyai sintaks yang dapat menumbuhkan kreatifitas siswa. Tujuan penelitian ini adalah untuk menguji perbedaan hasil belajar kreatifitas siswa yang dibelajarkan dengan model sinektik dan siswa yang belajar menggunakan model pembelajaran konvensional. Metode penelitian yang digunakan adalah kuasi eksperimen, Penelitian ini dilaksanakan pada bulan januari-februari 2020. Populasi penelitian ini adalah siswa kelas 3 di MI Bahrul Ulum Blawi dengan mata pelajaran bahasa Indonesia. Metode pengambilan sampel yang digunakan adalah cluster random sampling. Sampel dalam penelitian ini adalah 2 kelas dengan menggunakan sample random sampling, satu kelas sebagai kelas kontrol yang diajarkan menggunakan metode konvensional dan satu kelas sebagai kelas eksperimen yang diajarkan menggunakan model pembelajaran sinektik. Jumlah subyek penelitian kelas eksperimen sebanyak 22 siswa dan kelas kontrol berjumlah 20 
siswaAnalisis penelitian menggunakan independent sample t-test. Hasil penelitian menyimpulkan bahwa terdapat pengaruh antara model pembelajaran sinektik terhadap kreatifitas siswa pada pelajaran bahasa indonesia.

Kata Kunci: Evektivitas, Pembelajaran Sinektik, Kreatifitas 


\section{PENDAHULUAN}

Indonesia sebagai Negara berkembang sangat membutuhkan sumber daya manusia sebagai tenaga-tenaga kreatif yang mampu memberikan sumbangan bermakna kepada ilmu pengetahuan, teknologi, kesenian serta kepada kesejahteraan bangsa pada umumnya. Sudah tidak dipungkiri bahwa pebelajar kreatif menjadi solusi dalam pembangunan, gerakan yang kuat untuk memperbaiki pendidikan menekankan kepada hal yang disebut keterampilan abad 21 jenis-jenis keahlian yang telah maju ketika dunia global muncul (Joyce,2009) termasuklah didalamnya kreativitas. Greenstein (2012)

Kondisi terhadap pendidikan di Indonesia masih berorientasi pada pembelajaran yang bersifat satu arah, verbalistik, monoton, dan hapalan Lie (2004) sehingga pendapat Schmidt (2006) ditakutkan praktik pendidikan kurang mengapresiasi terhadap kemampuan kreatif anak. Penelitian catur Utami Munandar (1977) menunjukkan bahwa persepsi guru mengenai Peserta didik yang ideal hanya sedikit persamaannya dengan perilaku yang ditemukan pada pribadipribadi yang kreatif. Sebenarnya peran guru dapat mengembangkan kreativitas pebelajar yaitu berperan sebagai figur di kelas yang perilakunya akan ditiru oleh peserta didiknya dan berperan sebagai pencipta suasana kelas yang nyaman dan kondusif. Belajar kreatif Cropley (1994) menyebut mampu menimbulkan kepekaan atau kesadaran peserta didik akan masalah, kekuarangan-kekurangan, kesenjangan dalam pengetahuan, unsur-unsur yang tidak ada, ketidak harmonisan dan sebagainya. Mengumpulkam informasi yang ada, membataskan kesukaran, atau menunjukkan (mengidentifikasi) unsur yang tidak ada, mencari jawaban, membuat hipotesis, mengubah dan mengujinya, menyempurnakan dan akhirmnya mengkomunikasikan hasil-hasilnya

Menciptakan sumberdaya manusia yang kreatif dapat melalui pendidikan atau pembelajaran, dalam pandangan Beghetto (2016) kreativitas memiliki hubungan dengan pembelajaran yang disebutnya (creativity-in-learning) adalah lingkungan intrapsikologis, di mana penekanannya adalah pada peran yang dimainkan kreativitas dalam mengubah pemahaman pribadi (pebelajar) dan (learning-in-creativity) yakni bidang interpsikologi, di mana fokusnya adalah pada peran pembelajaran dalam memberikan kontribusi kreatif kepada orang lain. (Munandar, 2009) menyebut ciri pribadi yang kreatif yaitu: imajinatif, mempunyai prakarsa, mempunyai minat luas, mandiri dalam berpikir, senang berpetualang, penuh energi, percaya diri, bersedia mengambil risiko, dan berani dalam berpendirian dan berkeyakinan.

Menurut beberapa penelitian menunjukan bahawa pembelajaran bahasa Indonesia masih menggunakan metode konvensional dan monoton. Pada mata pelajaran bahasa Indonesia di Madrasah Ibtidaiyah sistem pembelajaran masih terbilang konvesional hanya terfokus pada membaca dan hafalan Rahayu (2016); Umar (2016) Hal tersebut tidak dapat mengasah kreatifitas peserta didik. Guna menyelesaikan permasalahan di atas diperlukan model pembelajaran yang dapat mengasah kreatifitas peserta didik.

Model pembelajaran sinektik memberikan kebebasan kepada peserta didik untuk menumpahkan segala ide dan gagasan yang ada dipikarannya tanpa memperdulikan tata bahasanya. Gordon dalam Joyce et al. (2009) mengatakan sinektik dirancang untuk meningkatkan kreativitas individu dan kelompok. Jadi bukan hanya untuk individual, namun peserta didik juga dapat mengembangkan dan mengeluarkan gagasan pada suatu masalah bersama dengan teman sekelasnya. Sinektik merupakan suatu pendekatan baru yang menarik guna mengembangkan kreativitas. Tujuan dari model ini adalah menumbuhkan kreativitas, sehingga diharapkan siswa mampu menghadapi setiap permasalahannya. Model ini menekankan segi penumbuhan kreativitas siswa. Kreativitas ini berhubungan dengan sikap emosional Suryaman (2012) .

Berdasarkan paparan latar belakang di atas, maka penelitian ini bertujuan untuk mengetahui pengaruh model pembelajaran sinektik dalam mengembangkan kreatifitas peserta didik pada mata pelajaran bahasa Indonesia di MI Bahrul Ulum Blawi

\section{Model Pembelajaran Sinektik}

Model pembelajaran sinektik adalah salah satu model pembelajaran yang termasuk dalam rumpun model pribadi Suryaman (2012) . Model sinektik pertama kali dikenalkan oleh William J.J. Gordon dalam bidang industri. Dia mengembangkan model ini untuk keperluan aktivitas individu dalam kelompok agar mereka dapat memecahkan suatu masalah (problem solver). Prinsip yang perlu dipegang dari model sinektik adalah jangan membatasi pengalaman yang mungkin diperoleh siswa, menghormati gagasan-gagasan siswa yang muncul, jangan menakuti siswa dengan nilai ujian, membiarkan siswa berproses 'liar', memberi ruang untuk mengadu pendapat, karena perbedaan individual sangat mungkin terjadi, kemudian memberikan motivasi siswa agar timbul ide-ide kreatif dan produktif.

\section{Sintaks Model Pembelajaran Sinektik}

Beberapa proses sinektik tertentu dikembangkan dari beberapa asumsi tentang psikologi kreativitas. Asumsi pertama, dengan membawa proses kreatif menuju kesadaran dan dengan mengembangkan bantuan-bantuan eksplisit menuju kreativitas, siswa dapat secara langsung meningkatkan kapasitas kreatif secara individu maupun kelompok. Asumsi yang kedua adalah bahwa komponen emosional lebih penting daripada intelektual, irasional lebih penting daripada rasional. Asumsi ketiga adalah bahwa unsur-unsur emosional, irasional harus dipahami dalam rangka meningkatkan kemungkinan sukses dalam situasi pemecahan masalah Joyce et al. (2009) .

Penjelasannya dalam Joyce et al. (2009) strategi satu diatas membantu siswa melihat hal-hal familier dengan cara yang tidak familier dengan analogi-analogi untuk menciptakan jarak konseptual. Kecuali tahap akhir dimana siswa kembali ke 
TABLE 1 | Sintaks untuk Strategi Satu: menciptakan sesuatu yang baru Joyce et al. (2009)

\begin{tabular}{|c|c|}
\hline $\begin{array}{l}\text { Fase Satu: } \\
\text { Mendeskripsikan } \\
\text { Kondisi yang ada }\end{array}$ & Guru meminta siswa menjelaskan situasi atau topic ketika mereka melihatnya sekarang \\
\hline $\begin{array}{l}\text { Fase Dua: } \\
\text { Analogi langsung }\end{array}$ & Guru meminta siswa menjelaskan situasi atau topic ketika mereka melihatnya sekarang \\
\hline $\begin{array}{l}\text { Fase Tiga: } \\
\text { Analogi personal }\end{array}$ & $\begin{array}{l}\text { Siswa menunjukkan analogi langsung, memilih satu analogi, dan mengeksplorasinya (mendeskrip- } \\
\text { sikan) lebih lanjut }\end{array}$ \\
\hline $\begin{array}{l}\text { Fase Empat: } \\
\text { Konflik yang dipersingkat }\end{array}$ & Siswa-siswa "menjadi" analogi yang mereka pilih di fase dua \\
\hline $\begin{array}{l}\text { Fase Lima: } \\
\text { Analogi Langsung }\end{array}$ & $\begin{array}{l}\text { Siswa mengambil deskripsi dari fase duadan tiga, menunjukkan beberapa konflik yang dipers- } \\
\text { ingkat, dan memilih satu }\end{array}$ \\
\hline $\begin{array}{l}\text { Fase Enam: } \\
\text { Menguji Kembali tugas Asli }\end{array}$ & $\begin{array}{l}\text { Siswa menghasilkan dan memilih satu analogi langsung lain, berdasarkan pada konflik yang } \\
\text { dipersingkat }\end{array}$ \\
\hline
\end{tabular}

TABLE 2 | Sintak untuk Strategi Dua: Membuat yang Aneh / Asing Menjadi Familier Joyce et al. (2009)

\begin{tabular}{ll}
\hline Fase Satu: & Guru memberikan informasi tentang topic baru \\
Input Substantif & Guru menunjukkan analogi langsung dan meminta siswa untuk mendeskripsikan analogi \\
$\begin{array}{l}\text { Fase Dua: } \\
\text { Analogi langsung }\end{array}$ & Guru meminta siswa "menjadi" 'analogi langsung \\
$\begin{array}{l}\text { Fase Tiga: } \\
\text { Analogi personal }\end{array}$ & Siswa-siswa mengidentifikasi dan menerangkan poin-poin kesamaan antara bahan yang baru dan analogi \\
Fase Empat: & langsung \\
Membandingkan Analogi & Siswa-siswa menerangkan di mana analogi tidak cocok \\
$\begin{array}{l}\text { Fase Lima: } \\
\text { Menerangkan perbedaan }\end{array}$ & Siswa-siswa mengeksplorasi kembali topic asli menurut istilah mereka sendiri \\
Fase Enam: & Siswa-siswa memeberikan analogi langsunnya sendiri dn mengeksplorasi pemahaman mereka terhdap \\
Eksplorasi & analogi tersebut \\
Fase Tujuh: &
\end{tabular}

masalah asli, mereka tidak membuat perbandingan sederhana.

Tujuan strategi ini memungkinkan untuk mengembangkan pemahaman baru; untuk berempati dengan show-off (sifat pamer) dan bully; untuk merancang pintu utama atau kota; untuk memecahkan masalah social, atau masalah antarpersonal, seperti pemogokan yang tidak perlu, atau dua siswa yang berkelahi; atau memecahkan masalah pribadi.

\section{Kreativitas}

Krativitas menurut Baron adalah kemampuan untuk menghasilkan atau enciptakan sesuatu yang baru. Begitu pula menurut Haefele mengatakan bahwa kreativitas adalah kemampuan untuk membuat kombinasi-kombinasi baru yang mempunyai makna sosial Munandar (2009)

Kreativitas dan pembelajaran misalnya, mendapatkan definisi belajar kreatif dengan menggambar pada definisi dan deskripsi kreativitas dan pembelajaran sebelumnya. Mereka mendefinisikan pembelajaran kreatif sebagai "pembelajaran yang mengarah pada pemikiran baru atau orisinal yang ada" Guilford (1956) bahwa "tindakan kreatif adalah contoh pembelajaran" dan menyarankan bahwa contoh pembelajaran kreatif adalah tindakan kreatif Beghetto (2016).

Konsep pembelajaran kreatif sebelumnya cenderung tidak mewakili secara penuh aktivitas belajar kreatif, saling bergantung hubungan antara kreativitas dan pembelajaran. Apalagi peran yang subjektif dan engalaman interpersonal yang dimainkan dalam proses pembelajaran sering dikaburkan.
Dengan demikian, konsep elajar kreatif mungkin mendapat manfaat yang terbagi menjadi dua sub konsepsi: kreativitasdalam-pembelajaran dan pembelajaran-dalam-kreativitas Yang pertama, kreativitas dalam pembelajaran, mengacu pada peran yang dimainkan kreativitas engembangan pemahaman pribadi. Yang kedua, belajar dalam kreativitas, mengacu pada eran yang saling berbagi dalam memainkan peran dalam memberikan kontribusi kreatif kepada orang lain Beghetto (2016). NACCCE mendefinisikan kreativitas sebagai aktivitas imajinatif yang dibuat sedemikian rupa sehingga menghasilkan hasil yang asli dan bernilai (National Advisory Committee for Creative and Cultural Education (NACCCE, 1999) . Kreativitas memainkan peranan dalam pembelajaran dengan memberi perhatian pada respon-respon emosional dan estetika terhadap pembelajaran, kreativitas akan meningkatkan pemahaman dan mendorong perkembangan. Kreativitas dapat mempertajam bagian-bagian otak yang berhubungan dengan kognitif murni. Dengan mengembangkan dan menggunakan semua kekuatan otak, pembelajaran akan bisa dimaksimalkan Brierley (1984) .

\section{Mata Pelajaran Bahasa Indonesia di MI}

Mata pelajaran bahasa Indonesia merupakan pembelajaran yang memberikan keterampilan bagi siswa untuk dapat berbahasa Indonesia yang baik dan juga benar. Bahasa Indonesia juga dapat digunakan sebagai alat komunikasi sosial atau alat yang dibutuhkan oleh seseorang agar dapat berinteraksi dengan orang lain. Bahasa sendiri memiliki empat keter- 
TABLE 3 | Indikator Berfikir Kreatif

\begin{tabular}{|c|c|}
\hline Indikator & Deskriptor \\
\hline Berpikir Lancar & $\begin{array}{l}\text { - Mengajukan banyak pertanyaan } \\
\text { - Menjawab dengan sejumlah jawaban jika ada pertanyaan } \\
\text { - Bekerja lebih cepat dari teman lain } \\
\text { - Melakukan lebih banyak dari pada teman yang lain } \\
\text { - Dengan cepat melihat kesalahan dan kelemahan dari suatu objek atau situasi }\end{array}$ \\
\hline Berpikir luwes & $\begin{array}{l}\text { - Memberikan macam-macam penafsiran terhadap suatu gambar, cerita atau masalah. } \\
\text { - Menerapkan suatu konsep atau asas dengan cara yang berbeda-beda } \\
\text { - Memberikan pertimbangan atau mendiskusikan sesuatu selalu memiliki posisi yang berbeda atau bertentangan } \\
\text { dengan mayoritas kelompok } \\
\text { - Jika diberi suatu masalah biasanya memikirkan macam-macam cara yang berbeda-beda untuk menyelesaikan- } \\
\text { nya }\end{array}$ \\
\hline Berpikir Orisinal & $\begin{array}{l}\text { - Memikirkan masalah-masalah atau hal yang tak pernah terpikirkan orang lain } \\
\text { - Mempertanyakan cara-cara lama dan berusaha memikirkan cara-cara baru } \\
\text { - Memberikan gagasan yang baru dalam menyelesaikan masalah } \\
\text { - Setelah mendengar atau membaca gagasan, bekerja untuk mendapatkan penyelesaian yang baru }\end{array}$ \\
\hline $\begin{array}{l}\text { Berpikir } \\
\text { Elaboratif }\end{array}$ & $\begin{array}{l}\text { - Mencari arti yang lebih mendalam terhadap jawaban atau pemecahan masalah dengan melakukan langkah- } \\
\text { langkah yang terperinci } \\
\text { - Mengembangkan/memperkaya gagasan orang lain } \\
\text { - Cenderung memberi jawaban yang luas dan memuaskan } \\
\text { - Mampu membangun keterkaitan antar konsep }\end{array}$ \\
\hline
\end{tabular}

TABLE 4 | Dimensi Berpikir Kreatif Vidal (2005)

\begin{tabular}{ll}
\hline Dimensi Creative Thinking & Deskripsi dimensi Creative Thinking \\
\hline Novelty & $\bullet$ Kemampuan memproduksi ide-ide baru \\
& $\bullet$ Kemampuan mengkombinasi ide-ide \\
& - Kemampuan memodifikasi ide-ide \\
Divergent Thinking & $\bullet$ Kemampuan memproduksi banyak ide \\
& $\bullet$ Mempunyai prespektif yang berbeda \\
& $\bullet$ Kemampuan berpikir imajinatifKemampuan mengembangkan ide-ide sulit
\end{tabular}

ampilan yaitu, menyimak, membaca, berbicara, dan menulis. Keempat komponen tersebut saling berhubungan dan harus seimbang sehingga dapat mendukung dalam proses berkomunikasi. Dengan adanya pembelajaran bahasa Indonesia di tingkat SD/MI maka sangat membantu dalam pengenalan bahasa sejak dini. Semakin dini pengajaran bahasa yang dilakukan oleh seorang guru maka siswa dapat lebih sering berlatih dan kemampuan berbahasa (berkomunikasinya) akan semakin baik. Karena tujuan dari bahasa Indonesia sendiri ialah untuk memudahkan seseorang agar dapat berkomunikasi dengan efisien dan tepat sesuai dengan etika yang berlaku di masyarakat.

Dalam penelitian ini untuk mengukur kreatifitas peserta didik dilaksanakan pada mata pelajaran bahasa Indonesia kelas 3 semester 2 pada tema 5. Pemilihan materi pembelajaran bahasa Indonesia dengan tema menulis dan mengarang cerita pendek sangat tepat dalam mengasah kreatifitas peserta didik. sanakan pada bulan januari-februari 2020. Populasi penelitian ini adalah siswa kelas 3 di MI Bahrul Ulum Blawi dengan mata pelajaran bahasa Indonesia. Metode pengambilan sampel yang digunakan adalah cluster random sampling. Sampel dalam penelitian ini adalah 2 kelas dengan menggunakan sample random sampling, satu kelas sebagai kelas kontrol yang diajarkan menggunakan metode konvensional dan satu kelas sebagai kelas eksperimen yang diajarkan menggunakan model pembelajaran sinektik. Jumlah subyek penelitian kelas eksperimen sebanyak 22 siswa dan kelas kontrol berjumlah 20 siswa. Pengumpulan data dilakukan dar nilai hasil belajar bahasa Indonesia pada materi menulis cerita pendek atau menarang cerita. Analisis penelitian menggunakan independent sample t-test untuk mengetahui ada dan tidaknya pengaruh model sinektik dalam mengembangkan kreatifitas peserta didik.

\section{METODE}

Penelitian ini merupakan penelitian kuantitiatif, yang didasarkan pada desain quasi eksperimen. Penelitian ini dilak- 


\begin{tabular}{|c|c|c|c|c|}
\hline Kelas & $\mathrm{N}$ & Mean & Std. Deviation & Std. Eror Mean \\
\hline Hasil belajar kelas eksperimen & $\begin{array}{l}22 \\
20\end{array}$ & $\begin{array}{l}86.3182 \\
68.000\end{array}$ & $\begin{array}{l}7.94856 \\
5.23148\end{array}$ & $\begin{array}{l}1.69464 \\
1.16980\end{array}$ \\
\hline
\end{tabular}

\section{HASIL DAN PEMBAHASAN}

\section{Perbandingan rata-rata hasil belajar dan kreatifitas pada kelas eksperimen dan kelas kontrol}

Pada tabel 5 diatas dapat dijelaskan bahwa nilai rata-rata hasil belajar pada kelas eksperimen sebesar 86,3182, sedangkan nilai rata-rata hasil belajar pada kelas kontrol adalah sebesar 68,0000. Dari data tersebut dapat disimpulkan bahwa nilai hasi belajar kelas eperimen yang mengunakan modep pembelajaran sinektik pada pembelajaran bahasa indonesia lebih baik daripada nilai hasil belajar siswa pada kelas kontrol yang menggunakan model konvensional.

Konsep dasar uji independent sample $t$ test dipergunakan untuk mengetahui apakah ada perbedaan hasil belajar anatara kelas eksperimen dan kelas kontrol. Dasar pengambilan keputusan pada uji independent sample t test adalah jika nilai sig (2tailed) $<0,05$ maka terdapat perbedaan yang signifikan antara hasil belajar kelas eksperimen dan kelas kontrol. Dari data pen-

\section{REFERENCES}

Beghetto, R. A. (2016). Creative Learning: A Fresh Look. Journal of Cognitive Education and Psychology 15, 6-23. doi: 10.1891/1945-8959.15.1.6.

Brierley, J. (1984). Human Birthright: Giving the Young Brain a Chance (London: BAECE).

catur Utami Munandar, S. (1977). Creativity and Education (Jakarta: Departemen Pendidikan dan Kebudayaan).

Cropley, A. J. (1994). More Ways Than One: Fostering Creativity (New Jersey: Albex).

Greenstein, L. (2012). Assesing 21st Century Skills: A Guide to Evaluating Mastery and Authentic Learning (California: Corwin A SAGA Company).

Guilford, J. P. (1956). The structure of intellect. Psychological Bulletin 53, 267-293. doi: $10.1037 / \mathrm{h} 0040755$.

Joyce, B. R., Weil, M., and Showers, B. (2009). Models of Teaching (Universitas Michigan: Allyn \& Bacon), 1-492.

Lie, A. (2004). Cooperative Learning, Memperaktikkan Cooperative Learning Di Ruang-Ruang Kelas (Jakarta: Gramedia).

Munandar (2009). Pengembangan Kreativitas Anak Berbakat (Jakarta: PT. Rineka Cipta).

Rahayu, Y. S. (2016). Penerapan Model Sinektik Berorientasi Berfikir Kreatif dalam Pembelajaran Menulis Deskripsi Siswa SMP. http://repository.unpas.ac. gujian independent sample t test diperoleh signifikansi yang berbeda yaitu nilai sig berada di bawah 0,05 . Nilai sig (2-tailed) sebesar 0.000, dan hipotesis diterima dengan kata lain bahwa kreatifitas siswa pada kelas eksperimen lebih baik daripada kelas kontrol. Maka dapat disimpulkan jika model pembelajaran sinektik lebih unggul daripada metode konvesnsional dalam mengembangkan kreatifitas siswa dalam mata pelajaran bahasa Indonesia.

\section{KESIMPULAN}

terdapat perbedaaan hasil belajar kreatifitas siswa yang dibelajarkan menggunakan model pembelajaran sinektik. kesimpulan dari penelitian ini juga menunjukan adanya peningkatan hasil belajar kreatifitas siswa setelah belajar menggunakan model sinektik pada pembelajaran bahasa Indonesia. Saran untuk penelitian lebih lanjut adalah agar peneliti selanjutnya untuk bisa mengembangkan kreatifitas siswa dengan menggunakan metode atau model pembelajaran yang lebih bervariatif dan berbasis HOTS.

$\mathrm{id} / 13961 /$.

Schmidt, P. B. (2006). Creativity And Coping Later Life. Generation 30, 27-31.

Suryaman, M. (2012). Metodologi Pembelajaran Bahasa (Yogyakarta: Univerisitas Negeri Yogyakarta Press)

Umar, M. (2016). Inovasi Pembelajaran Bahasa Indonesia Melalui Pendekatan Proses. Jurnal Retorika 9, 90-106. doi: https://doi.org/10.26858/retorika.v9i2. 3806.

Vidal, R. V. V. (2005). Creativity for Operation Researchers. Portugal: Investigation and Operational. Investigation and Operational 25. doi: https://doi.org/10.1590/ S0101-74382006000100004

Conflict of Interest Statement: The authors declare that the research was conducted in the absence of any commercial or financial relationships that could be construed as a potential conflict of interest.

Copyright $(2020$ Pramusinta and Rifanah. This is an open-access article distributed under the terms of the Creative Commons Attribution License (CC BY). The use, distribution or reproduction in other forums is permitted, provided the original author(s) and the copyright owner(s) are credited and that the original publication in this journal is cited, in accordance with accepted academic practice. No use, distribution or reproduction is permitted which does not comply with these terms. 